\title{
IDIOPATHIC DIFFUSE MUSCULAR HYPERTROPHY LOWER OESOPHAGUS
}

\author{
BY \\ J. C. SLOPER \\ From the Bernhard Baron Institute of Pathology, The London Hospital, E.I
}

(RECEIVED FOR PUBLICATION DECEMBER 21, 1953)

There is a curious and little-known pathological change in the oesophagus in which the musculature of the lower half is greatly and diffusely thickened whilst the lumen is of normal diameter. This condition was probably described by Matthew Baillie in 1799, but since then has attracted little interest. It seems justifiable to add a further seven cases to the 25 reported in the literature. An attempt will be made to clarify the aetiology of this condition. Attention will also be drawn to the means by which it may be diagnosed in life, for it will be shown that the underlying functional disturbance is probably a diffuse lower oesophageal spasm, a change which has in recent years been recognized with increasing frequency by radiologists, but about the pathology of which little is as yet known.

\section{CASE RePORTS}

CASE 1 (Index number 30351/1923. Medical).G. H., a man aged 53 years, was admitted to the London Hospital on January 31, 1923. For the past two months he had had a cough with pain in the chest and dyspnoea. He had lost a great deal of weight. His condition deteriorated and he died on March 5, 1923.

The patient had no history relevant to the oesophagus.

Summary of Necropsy (P.M. 121/1923).-There was a carcinomatous mass ( 9 by 6 by $6 \mathrm{~cm}$.) in the hilum of the left lung, with great infiltration of the hilar glands. This growth was composed of solid acini of oat cells and spindle cells, and of tubules lined by cubical and columnar epithelium. There were numerous secondaries in the liver and bones. The lower lobe of the left lung showed bronchopneumonia. The heart was slightly enlarged $(361 \mathrm{~g}$.).

Appearance of the Oesophagus.-There was hypertrophy without dilatation of the oesophagus, gradually increasing from the upper end $(0.3 \mathrm{~cm}$. thick) to the lower end $(1 \mathrm{~cm}$. thick), but without any additional thickening at the cardia. The mucosa was white and smooth.

Microscopical Appearances.-The epithelium of the lower oesophagus was normal. A longitudinal section at this level showed great hypertrophy of the muscle coats, and in particular of the inner circularos layer (Fig. 1). There was no evidence of inflammao tion and the myenteric ganglia were normal.

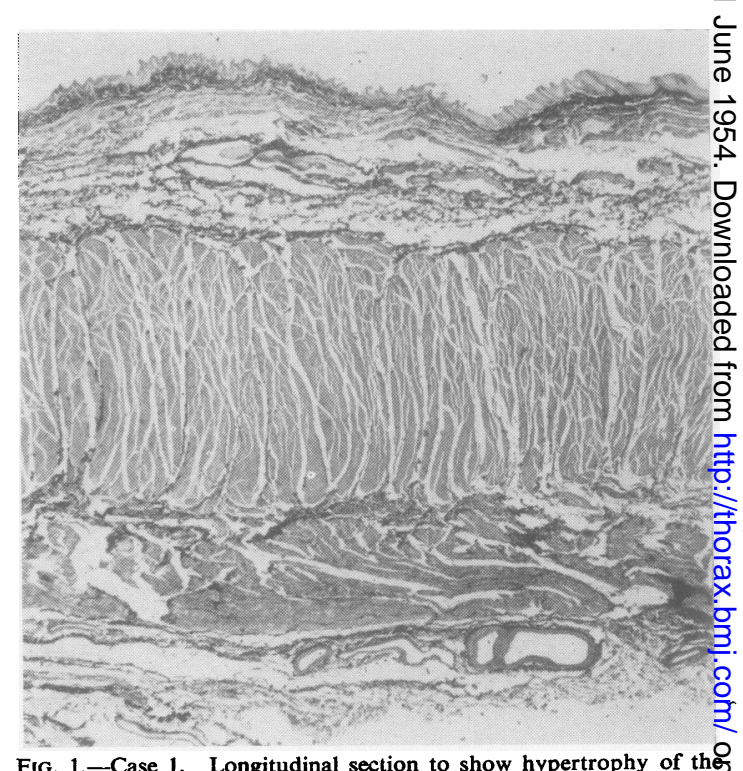

FIG. 1.-Case 1. Longitudinal section to show hypertrophy of the muscularis. Van Gieson $\times 8$.

CASE 2 (Index number 10258/52).-M. B., a woma年. aged 31 years, was admitted to the London Hospital on March 31, 1952. For some five weeks she had been dyspnoeic and had had difficulty in swallowing solid food. She had lost a great deal of weight. Twe weeks before admission she had attended a chest clinic, where a retrosternal goitre was diagnosedo On examination there was very great dyspnoea. hard mass was felt at the base of the neck. Am immediate operation was performed to remove this mass and relieve the tracheal obstruction. The operation proved unsuccessful, and in spite of tracheo tomy the patient died two hours afterwards.

Her husband and a brother later stated that aparD from repeated quinsies she had been in reasonable health, although for the past five years she had suf fered from indigestion and attacks of " tight" uppeo 
abdominal pain during meals. Dysphagia was only terminal, and she never vomited. The patient had worked at a comptometer in the Post Office until shortly before her death, and there was nothing to suggest myopathy.

Summary of Necropsy (P. M. 127/1952).-A carcinoma of the thymus (10 by 7 by $5 \mathrm{~cm}$.) occupied the anterior mediastinum, at its lower part keeping the shape of the organ, superiorly invading the thyroid, and laterally infiltrating the pleural surface of the upper lobes of both lungs. Both vagi entered this growth, which enveloped the structures passing through the superior mediastinum, causing stenosis of the trachea and invading the muscularis of the left half of the upper $5 \mathrm{~cm}$. of the oesophagus. The heart was not enlarged (227 g.).

Appearance of the Oesophagus. - There was great hypertrophy of the lower two-thirds, and in particular of the lower third, of the oesophagus (Fig. 2); the upper oesophagus measured $3.5 \mathrm{~cm}$. circumference and $0.25 \mathrm{~cm}$. thick ; the lower, $2.2 \mathrm{~cm}$. circumference and $0.8 \mathrm{~cm}$. thick. The thickening was largely of the inner circular muscle coat, although muscularis mucosae and the outer longitudinal muscle coat were also thickened. The epithelium was smooth and white and.showed longitudinal folds. The stomach

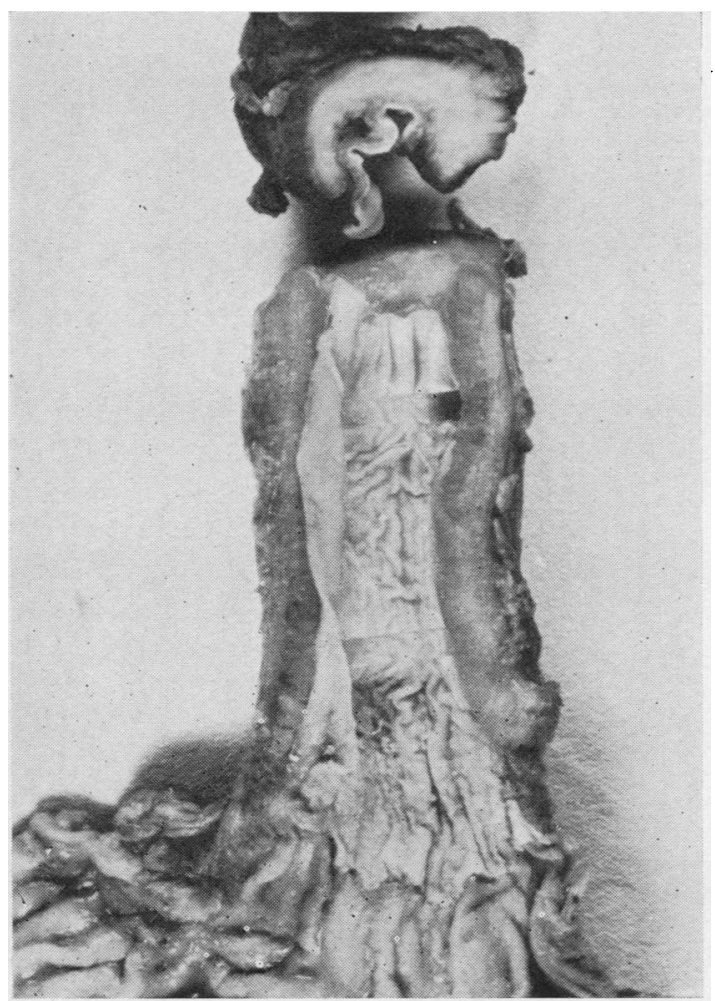

FIG. 2.-Case 2. Lower oesophagus to show uniform thickening of the wall and normal mucosa at the cardia was normal and undilated. There was no evidence of ulceration either at the pylorus or the cardia, and the pylorus was unthickened.

Microscopical Appearances.-There is great thickening of all three coats of the oesophagus (Fig. 3, cf. Fig. 4 for the normal appearance) beginning at the

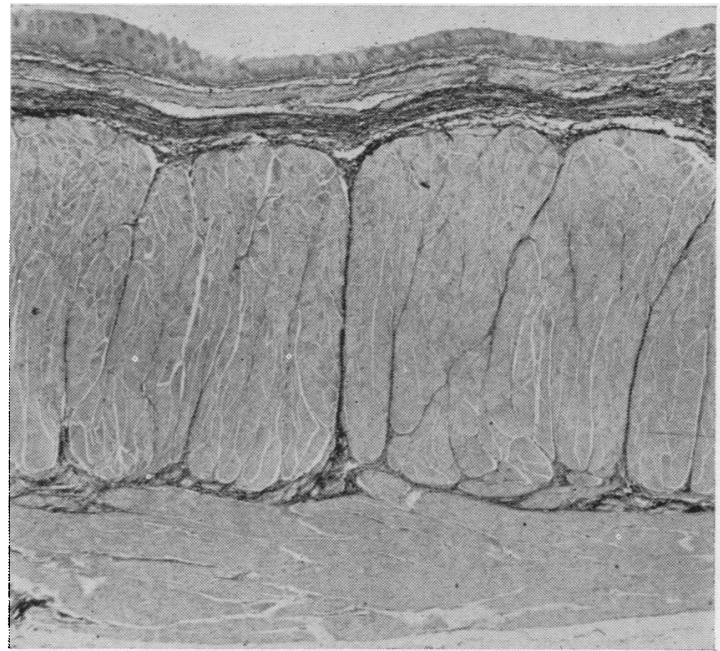

FIG. 3.-Case 2. Longitudinal section of the lower oesophagus for comparison with Fig. 4. Van Gieson $\times 10$.

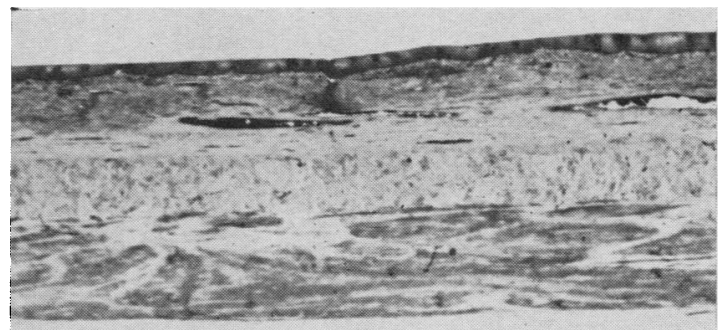

FIG. 4.-Longitudinal section of normal lower oesophagus. Haematoxylin and $\operatorname{cosin} \times 10$.

transition between smooth and skeletal muscle, remaining maximal throughout the distal third of the oesophagus, and diminishing rapidly in the first $2 \mathrm{~cm}$. (in the section) of the stomach. Focally, and largely confined to the intermuscular septa between the inner circular and outer longitudinal muscle coats, there is a cellular infiltration composed partly of lymphocytes and partly of eosinophil leucocytes. These are largely perineural (Fig. 5) and perivascular (Fig. 6) : they infiltrate Auerbach's plexus, but the ganglia and nerve fibres are normal (GrossBielchowsky preparation). This infiltration is present in the stomach below the cardia, and focally throughout the oesophagus. It is most marked in the lower third, although not particularly so at the cardia, and is relatively slight in the upper third. The left half of this portion of the oesophagus is infiltrated by a 


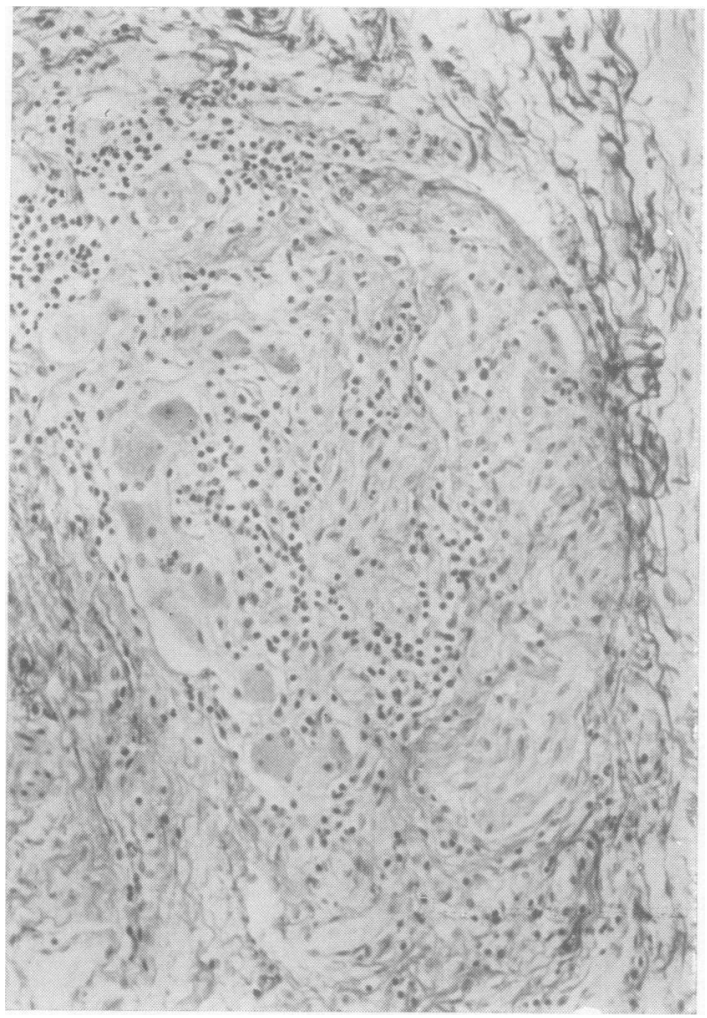

FIG. 5.-Case 2. Section from oesophagus about $10 \mathrm{~cm}$. above the cardia. Lymphocytic infiltration of Auerbach's plexus. Van Gieson $\times 160$

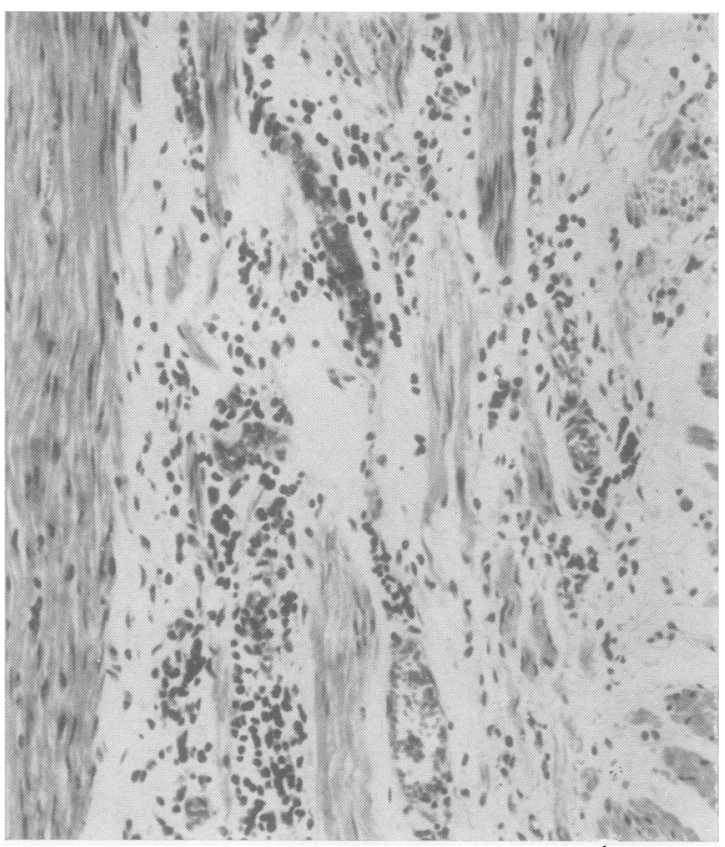

FIG. 6.- Case 2. Section from the oesophagus about $3 \mathrm{~cm}$. above the cardia. Infiltration of intermuscular connective tissue in the region of Auerbach's plexus by lymphocytes and eosinophil leucocytes (latter indistinguishable at this magnification). Haematoxylin and eosin $\times 160$.
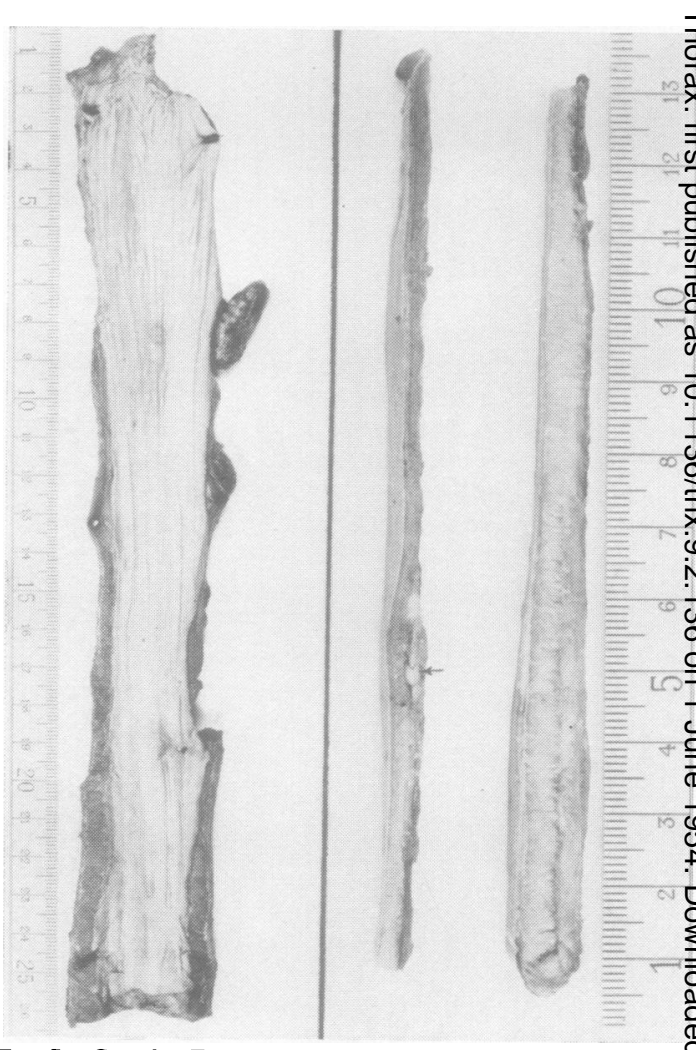

FIG. 7.--Case 3. To left, opened oesophagus, with hypertrophy of the muscularis in the lower half. To right, longitudinal section of the entire wall in two pieces, the left the upper half, the rigit the lower half. Note nodules of growth in the muscularis

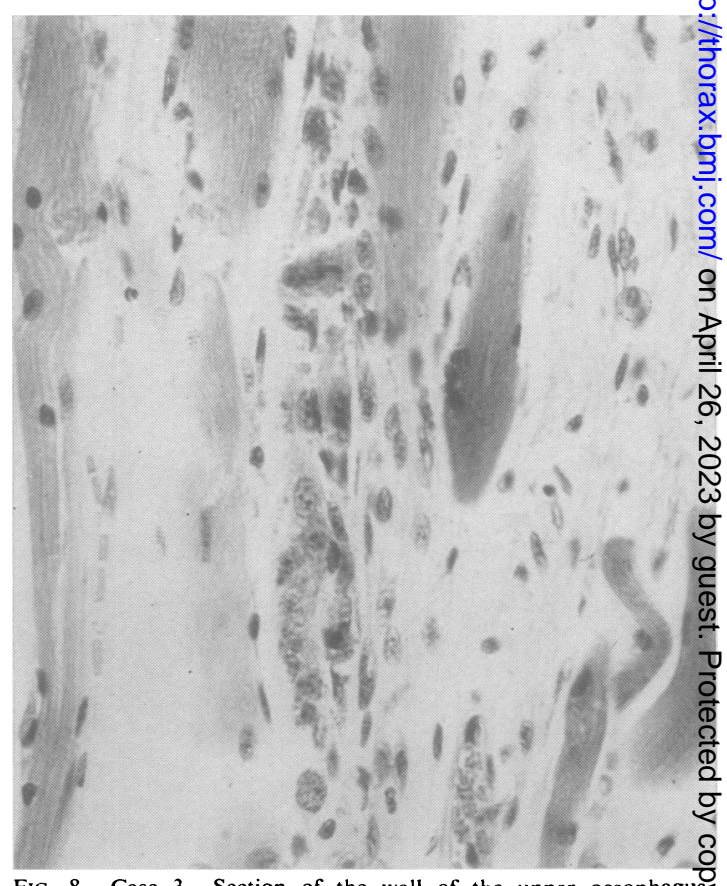

FIG. 8.--Case 3. Section of the wall of the upper oesophagus The skeletal muscle fibre is degenerated with local aggregation of muscle-cell nuclei. Haematoxylin and eosin 360 . 
lymphoepithelioma of the thymus, locally destroying muscularis and extending into the submucosa. The epithelium here is hyperplastic, and is again hyperplastic in the lower oesophagus. Sections of pharynx and pylorus are normal, but in a section from the abductor digiti minimi, one of many sections of skeletal muscle, there is a single lymphorrhage. Sections of both vagi near their entry into the growth show early carcinomatous invasion of the perineurium.

CASE 3 (Index number $4110 / 51$ ).-A. S., a man aged 58 years, was admitted on December 22, 1952 . For the preceding three months he had had a severe cough and had become dyspnoeic in the last month. In this period he had also noticed an ache in the lower back radiating down the left leg. Radiographs revealed shadows in the upper and medial zones of the left chest, and hilar shadows : several ribs were eroded. The patient became increasingly dyspnoeic, and died on February 2, 1953.

There was no history relevant to the oesophagus.

Summary of Necropsy (P.M. 64/1953).--There was a large, soft, retro-peritoneal mass $(12$ by $7.5 \mathrm{~cm}$.) in the left pelvis, partially encapsulated, but attached to and eroding the wing of the ilium, and thus communicating with a similar mass in the left gluteal muscles; the cut surface of this tumour was peripherally opaque, white and soft, but centrally purple and necrotic. There was no growth in inguinal, lumbar or para-aortic glands, but the hilar and lower cervical glands were diffusaly infiltrated, the former forming a mediastinal mass (about 9 by 6 by $6 \mathrm{~cm}$.), which pressed on neither trachea nor oesophagus. In the upper left lobe there was an encapsulated mass of similar growth ( 6 by 5 by $3.5 \mathrm{~cm}$.), elevated up to $2.8 \mathrm{~cm}$. above the adjacent pleura and attached to the parietal pleura. Between this and the hilum there was no intervening growth. A second extrapleural mass ( 5 by 4 by $4 \mathrm{~cm}$.) eroded the inner surface of the right fifth and sixth ribs. The vagi were attached to, but at no point surrounded by, growth. There was a severe mucopurulent bronchitis. The heart was enlarged (567.5 g.). There were two lipomas, both encapsulated, one (3.2 by $1.2 \mathrm{~cm}$. diam.) adjacent to the right spermatic cord, the other $(6.5$ by $3.7 \mathrm{~cm}$. diam.) in connective tissue overlying the left fourth and fifth ribs. The testes were normal.

Appearance of the Oesophagus.-There was hypertrophy without dilatation of the lower oesophagus (Fig. 7). The upper oesophagus measured $3.2 \mathrm{~cm}$. circumference and $0.3 \mathrm{~cm}$. thick. At $9.5 \mathrm{~cm}$. below the cricoid it measured $3 \mathrm{~cm}$. circumference and $0.4 \mathrm{~cm}$. thick, but below this point the thickness increased, being $0.6 \mathrm{~cm}$. $18 \mathrm{~cm}$. below the cricoid and uniformly $0.8 \mathrm{~cm}$. to $1 \mathrm{~cm}$. in the distal $7 \mathrm{~cm}$. of the oesophagus. There was a small area of leukoplakia $(0.4 \mathrm{~cm}$. diameter) $9.5 \mathrm{~cm}$. below the cricoid, and the hypertrophied part of the oesophagus was also slightly leukoplakic. Between 5.5 and $10 \mathrm{~cm}$. below the cricoid there were nodules of growth (up to $2.5 \mathrm{~cm}$. by $0.5 \mathrm{~cm}$. diameter) in the anterior peri-oesophageal connective tissue, this growth focally also infiltrating the oesophagus.

Microscopical Appearances.-The pelvic, right subpleural, and hilar masses are composed of partly encapsulated, partly infiltrating, pleomorphic and often multinucleate, sometimes spindle-celled sarcoma. Transverse cytoplasmic striations are absent, and the tumour cells cannot be identified with any single connective tissue element.

This sarcoma focally infiltrates and destroys the outer coat of the middle oesophagus. In this area, and in the peri-oesophageal tissue, the lesser bundles of the vagus are, in places, surrounded by growth. There is a similar but slight sarcomatous infiltration of the connective tissue adjacent to the main trunks of the vagi.

Appearances of the Oesophagus.-The muscle coats of the lower oesophagus are greatly hypertrophied. Here, and also in the upper oesophagus, there is a slight focal lymphocytic infiltration in the region of Auerbach's plexus, but in Bielchowsky preparations the nerves are normal. In the upper oesophagus many skeletal muscle fibres are swollen, hyaline and eosinophilous. In some fibres there is destruction of sarcoplasm, and in other fibres the sarcoplasm is basophilic, with local aggregations of muscle cell nuclei (Fig. 8).

CASE 4.- (This case is published by courtesy of Dr. J. S. Harris, Superintendent of Claybury Mental Hospital, and Dr. A. C. Hunt, of the Bernhard Baron Institute of Pathology, The London Hospital.)

F.V., a railway-foreman aged 60 years, was admitted to Claybury Mental Hospital in February, 1953, in a confused and disorientated state. Two years previously he had suffered a transient left hemiplegia and was found to be hypertensive (blood pressure $220 / 110 \mathrm{~mm}$. $\mathrm{Hg}$ ). He suffered several attacks of encephalopathy and died in June, 1953.

For some 36 years there had been occasional attacks of epigastric pain, more marked in the last 19 years. A gastric ulcer was diagnosed nine years before death, and had ceased to give trouble some four years later. A gastroscopy was performed without difficulty in 1949 by Dr. Frankel. In these last few years he occasionally brought up slime at night, but there was no history of dysphagia.

He had been a delicate child and was brought up on a vegetarian diet. He had always been overanxious. His second son possibly had infantile pyloric stenosis.

Pathological Findings.-Necropsy was performed by Dr. A. C. Hunt at Claybury Mental Hospital, and showed cerebral oedema, left cerebral spongioblastoma multiforme, cardiovascular hypertrophy, and healed gastric ulcer, pyloric muscular hypertrophy, and diffuse muscular hypertrophy of lower oesophagus.

The Appearance of the Oesophagus.-The oesophagus was $29 \mathrm{~cm}$. long and weighed over $61 \mathrm{~g}$., being 
greatly thickened in its lower half (Fig. 9), the wall measuring $0.2 \mathrm{~cm}$. thick at the cricoid and 0.6 to $0.8 \mathrm{~cm}$. in the lower third, the thickness diminishing rapidly in the distal $2.5 \mathrm{~cm}$. The lumen was of normal calibre, varying between 3.2 and $3.5 \mathrm{~cm}$. in circumference. The stomach was greatly dilated, but the wall was not thickened save at the pylorus. Here there was localized muscular hypertrophy, maximal over about a third of the circumference (up to $1.5 \mathrm{~cm}$.

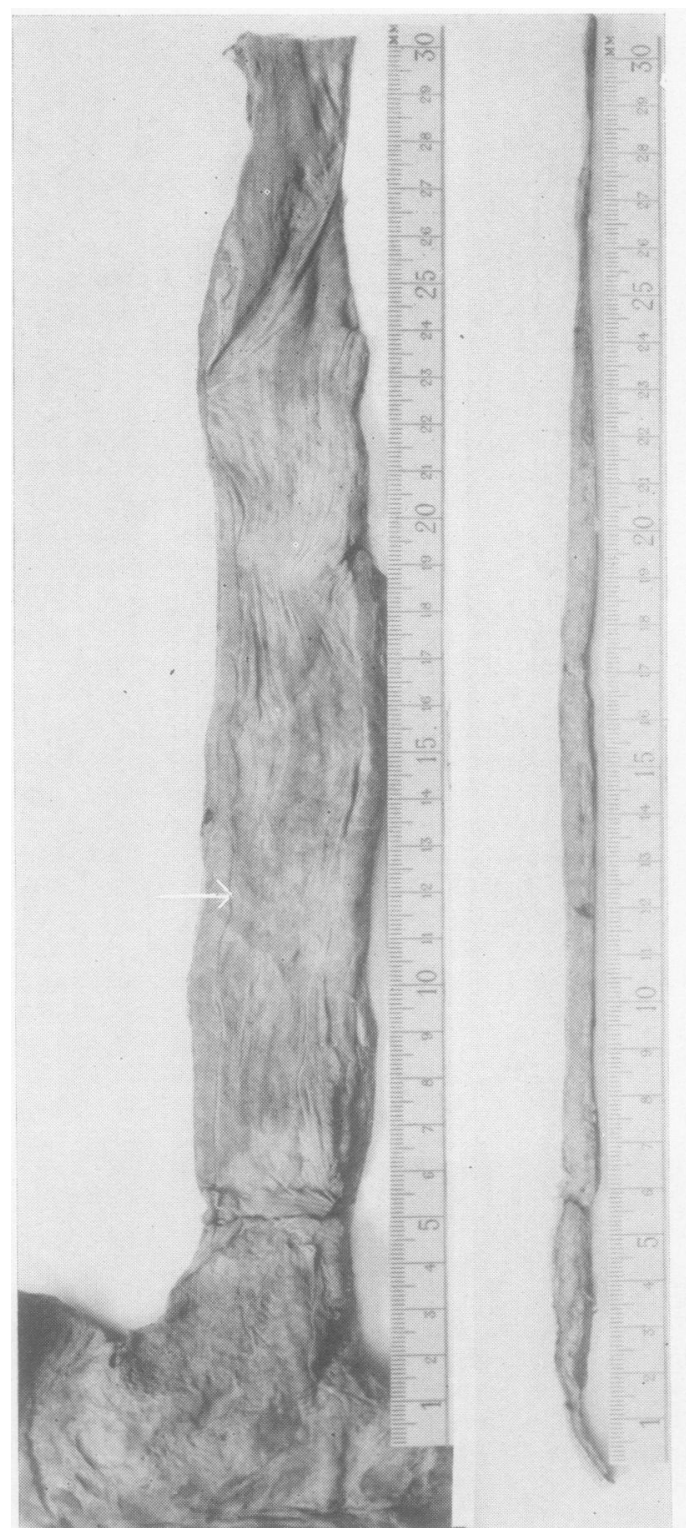

thick) and fairly marked in the remainder $(0.9 \mathrm{~cm}$ thick), but not obviously involving the antrum. The internal circumference measured $3.7 \mathrm{~cm}$. There was the scar of a peptic ulcer on the lesser curve $7 \mathrm{crD}$. above the pylorus.

Microscopical Appearances.-There is great muş cular hypertrophy of the lower oesophagus with conspicuous widespread focal lymphocytic and occasionally eosinophil cell infiltration of the deep intert

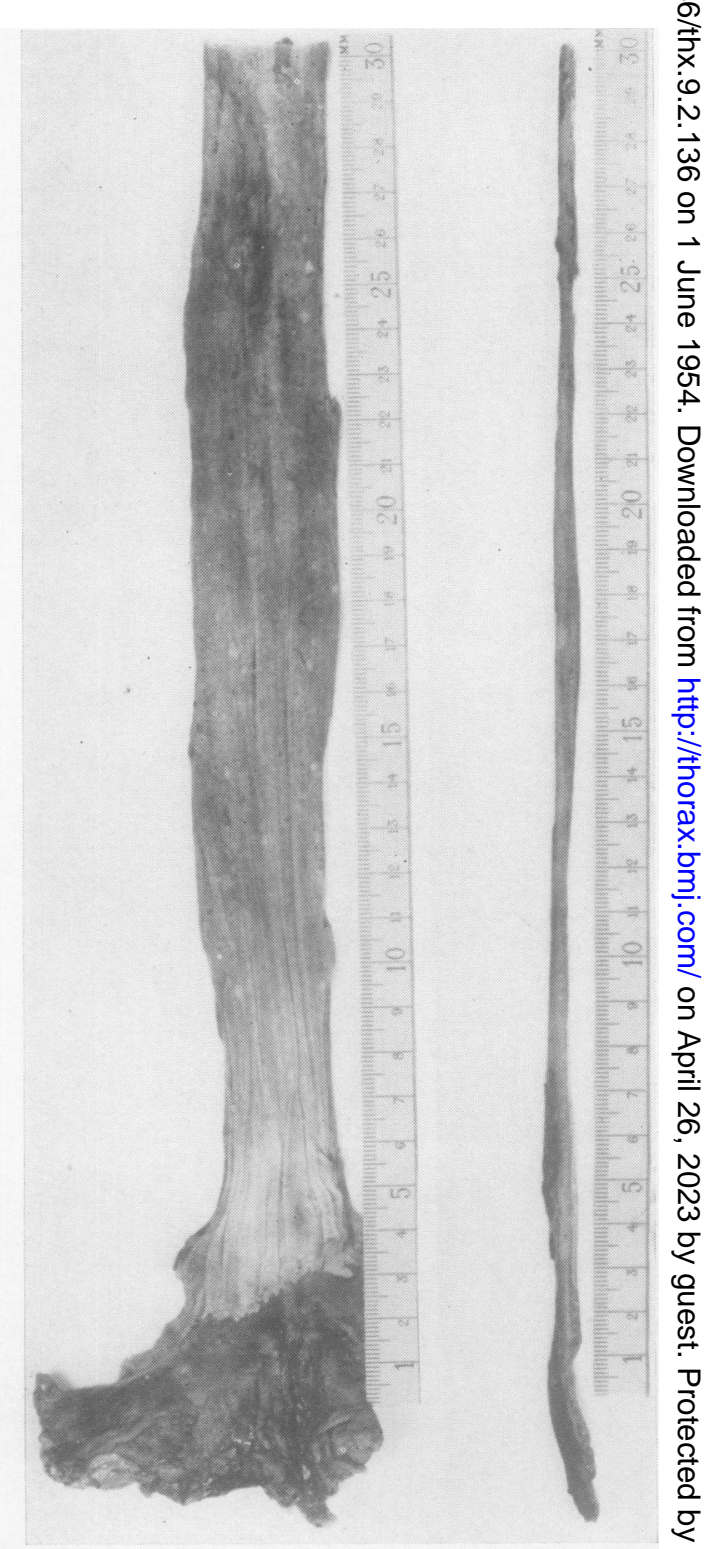

9. 4 . cardia cannot be identified.) An arrow marks the edge of the mucosa. On right, normal oesophagus, opened and on longitudinalo section. 


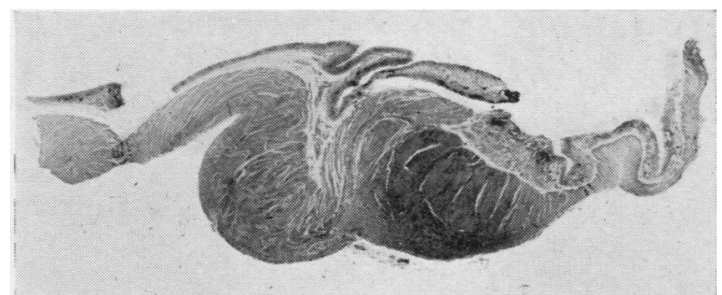

FIG. 10.-Case 4. Longitudinal section of the pylorus (duodenum to right). Great hypertrophy of the muscularis. Haematoxylin and $\operatorname{cosin} \times 2 \frac{1}{4}$

muscular septa. This involves the upper oesophagus also, but not the stomach or pylorus. The ganglia are normal. There is great muscular hypertrophy at the pylorus (Fig. 10), the inner fibres being particularly affected. Many fibres run irregularly in the hypertrophied area. There is a fibrous scar of an ulcer replacing muscularis on the lesser curve of the stomach; its surface is re-epithelialized.

CASE 5.-(This case is published through the kindness of Mr. P. R. Allison, Director of the Thoracic Unit, Professor A. S. Johnstone, Director of the Radiodiagnostic Unit, and Professor R. A. Willis, Director of the Pathological Department, the General Infirmary at Leeds.)

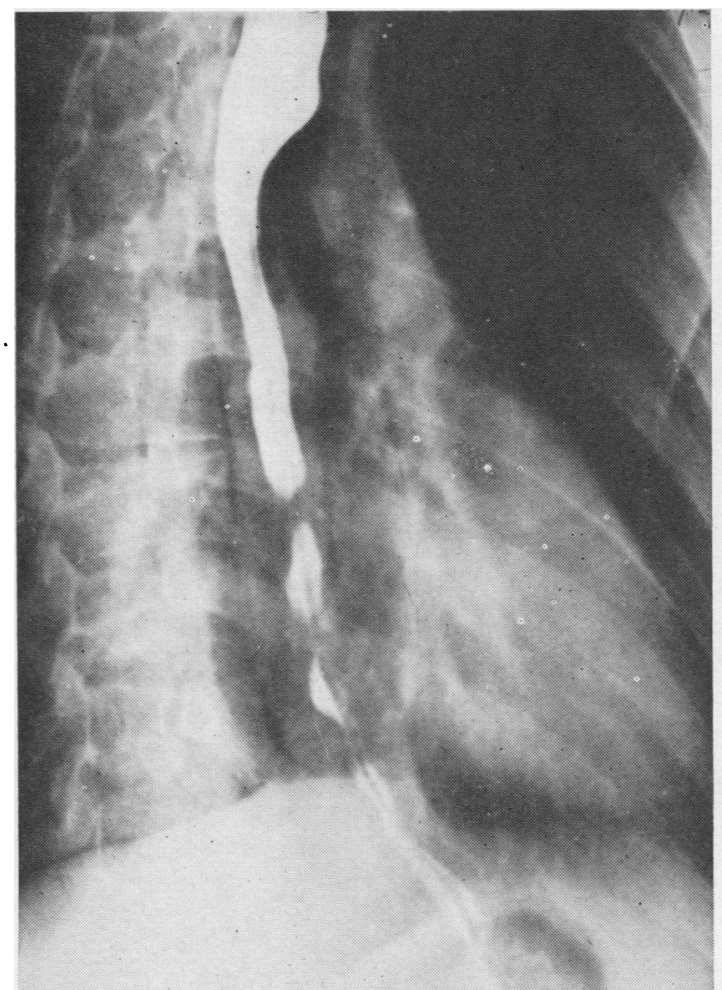

FIG. 11.-Case 5. Radiograph to show diffuse segmental contractions in the lower oesophagus.
T. V., an insurance clerk aged 41 years, was admitted to the General Infirmary at Leeds in 1946 complaining of epigastric pain coming on one hour after meals and relieved by food. He had also noticed for four years that particularly when he was irritated there was an uncomfortable but not painful sensation of food "piling up" behind the sternum. He frequently vomited before breakfast.

On examination the abdomen was tender, and radioscopy revealed a duodenal ulcer. There were also diffuse, sometimes segmental, contractions (Fig. 11) of the lower oesophagus. Oesophagoscopy confirmed the presence of spasm. In the next three years there was clinical and radiological evidence of the healing of the duodenal ulcer, although there were still daily attacks of high left epigastric pain. The patient gradually lost weight. The following symptoms were prominent: (1) Dysphagia, both for solids and liquids, (2) regurgitation, (3) heartburn, (4) mucusvomits, either in the early morning or at night.

In November, 1949, he was re-admitted. The blood pressure at this time was $125 / 80 \mathrm{~mm}$. Hg. Oesophagoscopy and radioscopy confirmed the presence of diffuse spasm. A carcinoma could not be excluded, and therefore a thoracotomy was performed. It was found that the oesophagus was greatly thickened, the thickening ending about $4 \mathrm{~cm}$. above the hiatus, where there was no hernia. A high bilateral vagotomy was performed and a biopsy taken from the thickened oesophagus. This revealed on microscopy great hypertrophy of the muscle coats. There was an eosinophilic and lymphocytic infiltration of the intermuscular septa.

Radioscopy a week after vagotomy revealed tertiary lower oesophageal contractions, and delay in the passage of solid but not fluid barium. On examination five months later the upper oesophagus was seen to "blow up" like a balloon. However, although at this time there was still spasm-without delay-six months later the lower oesophagus was found to behave like a " relatively inert tube," apparently emptying by gravity, lacking in peristalsis, and unaffected by octyl nitrite. This lower segment was pouched and irregular in appearance. The duodenum was normal.

The dysphagia was by now giving pain, vomiting was more frequent, and there was great loss in weight. Accordingly, in January, 1951, the affected segment was resected. The uppermost part of the oesophagus was not involved. An oesophago-jejunostomy was performed with a Roux loop. The symptoms were relieved, but the patient, a year later, developed phthisis, and is now in a sanatorium.

There is no relevant previous history. The patient has 10 children. He has always been over-anxious.

Pathological Findings.-The resected portion of oesophagus (Fig. 12) measured about $18 \mathrm{~cm}$. in length. At about $3 \mathrm{~cm}$. and $9 \mathrm{~cm}$. below its upper end the lumen was narrowed by two mucosal folds. The oesophageal wall was diffusely thickened (up to $1 \mathrm{~cm}$.). 


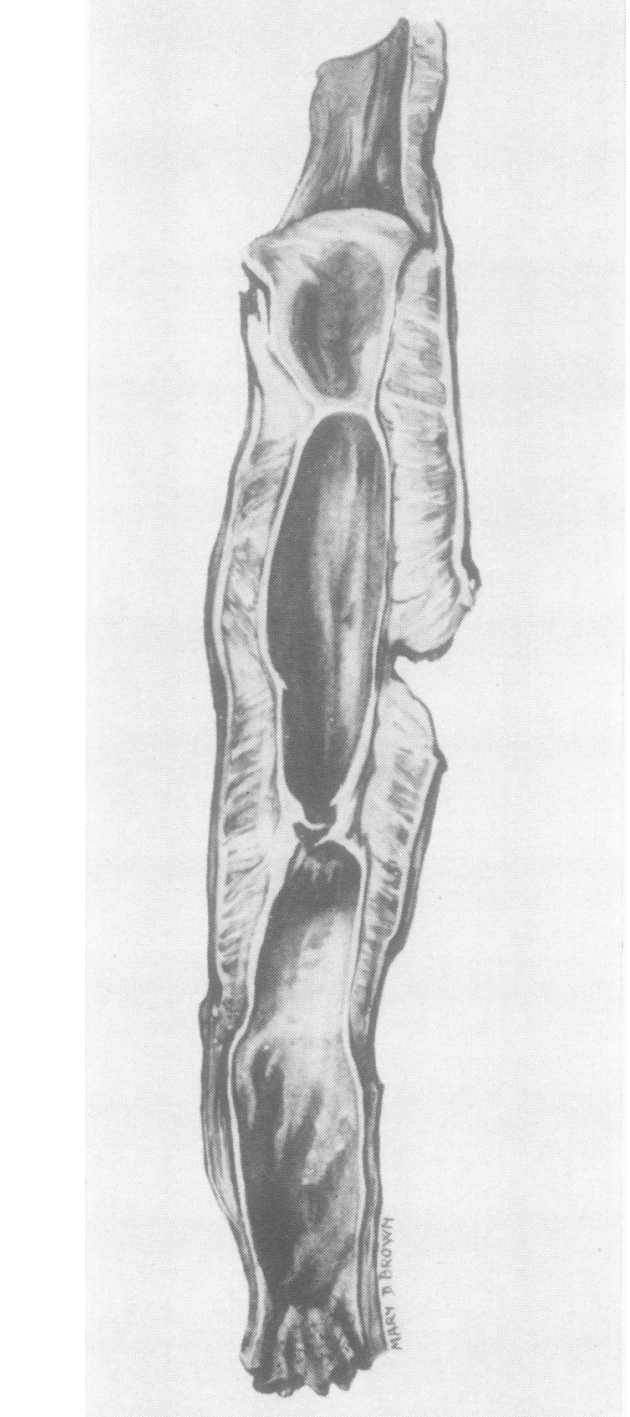

FIG. 12.-Case 5. Photograph of a painting of the resected segment of oesophagus. The muscular hypertrophy ends above the cardia. There are two mucosal folds. The mucosa has been stripped from the upper part of the oesophagus.

Microscopical examination reveals great muscular hypertrophy. There is slight subepithelial lymphocytic infiltration, and there are foci of lymphocytic and eosinophilic infiltration in the deep intermuscular septa. Occasional smooth muscle fibres show lipochrome granules. a change seen more conspicuously in the biopsy of 1949. The folds (Fig. 13) are composed of epithelium, subepithelial connective tissue, and muscularis mucosae.

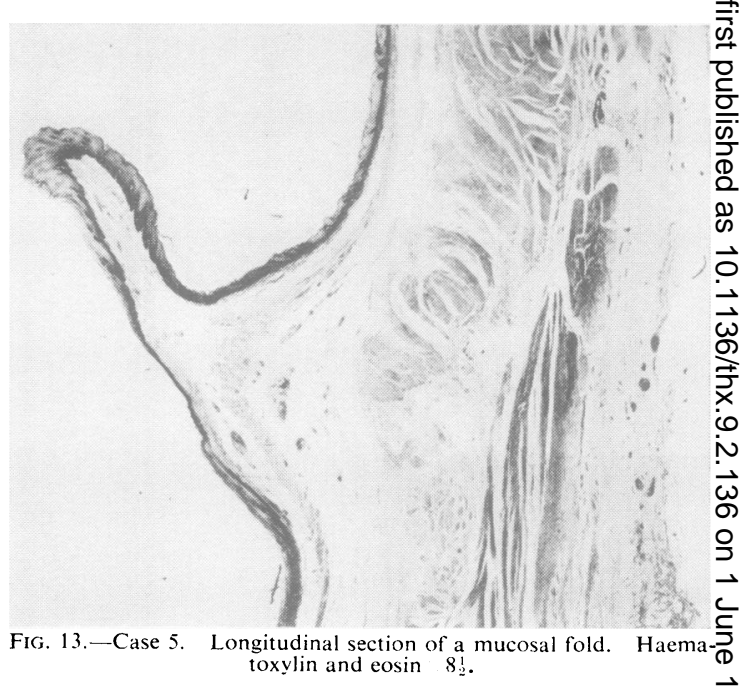

CASE 6 (Index number 11707/1924).--J. H., a man aged 63 years, was admitted on May 18, 1924. For four years he had had difficulty in micturition, ando for three years, but less in the last year, attacks of post-prandial pain in the epigastrium. In the last fouro months he had had attacks of diffuse abdominal pain.ׁ and pain on defaecation, with terminal loss of control $\mathbb{Q}$ of the anal sphincters. On examination, the patient was emaciated. There was visible colic peristalsis. and an ulcerated growth was felt in the rectum. This proved inoperable, and following a colostomy the? patient died of bronchopneumonia.

There was no history relevant to the oesophagus.

Summary of Necropsy (P.M. 270/1924).-A car-응 cinomatous ulcer almost encircled the rectum. No secondaries were found. Above the colostomy the colon was slightly dilated $(7.5 \mathrm{~cm}$. circumference). Int. the upper wall of the duodenum was the stellate scaro of an ulcer $(4 \mathrm{~cm}$. long), reaching to within $1.5 \mathrm{~cm}$. of the pylorus. There was myoadenomatous enlarge-o ment of the prostate, cystitis of the hypertrophied bladder, and bilateral ascending pyelonephritis. Ino the lower lobe of the lung were numerous areas of bronchopneumonia and abscess cavities. The heart was not enlarged (304 g.).

Appearance of the Oesophagus.-There was great hypertrophy of the muscle coat $(0.6 \mathrm{~cm}$. thick $)$ of the undilated oesophagus $(3.5 \mathrm{~cm}$. circumference). The mucosa was smooth and white.

No material was taken for microscopy.

CASE 7 (Index number 13785/1938. Surgical).T.W., a man aged 47 years, was last admitted on July 11,1940 , in extreme cachexia and died two days $\overrightarrow{\mathbb{D}}$ later. Twenty months previously there had been $\mathrm{a} \stackrel{?}{\mathbb{P}}$ gradual onset of abdominal pain accompanied byำ constipation. At laparotomy a carcinoma of the caecum was identified, and a right hemicolectomy. followed by ileocolic anastomosis, performed. Sub $=$ O sequently, and in spite of repeated irradiation, an 
abdominal mass again developed. Terminally, there was repeated vomiting and the abdomen showed visible peristalsis. The patient became comatose and died.

There was no history relevant to the oesophagus.

Summary of Necropsy (P.M. 127/1940).-There was a mass of growth filling the lumen of the ileocolic anastomosis and invading the mesentery of the small intestine. The mucosa of the ileum, the lumbar glands, and the liver contained nodules of secondary growth.

The ileum was slightly dilated above the anastomosis (up to $8.5 \mathrm{~cm}$. circumference), but less so higher up; the duodenum was considerably dilated $(11 \mathrm{~cm}$. circumference), but the stomach less so $(23 \mathrm{~cm}$. circumference). The heart was unenlarged (227 g.).

Appearance of the Oesophagus.-There was muscular hypertrophy $(0.5 \mathrm{~cm}$. thick) and slight contraction of the lower half of the oesophagus.

No material was taken for microscopy.

\section{Discussion}

The condition of diffuse muscular hypertrophy of the undilated lower oesophagus is apparently uncommon, for only 25 cases can be found in the literature similar to the seven described here (Baillie, 1799 ; Reher, 1885 ; Pitt, 1888 ; Rolleston, 1899 ; Elliesen, 1903 ; Ehlers, 1907 ; Rake, 1926 ; Brücke, 1928 ; Goedel, 1929 ; Wood, 1932 ; Helmke, 1939 ; Bühler, 1943 ; Guthrie, 1945 ; Giampalmo, 1946 ; Jemmi, 1947 ; Buccellato, 1948). Of the entire 32 cases only 25 have microscopical descriptions. It is of interest that the majority were men in their sixth and seventh decades, their ages ranging between 39 and 74 . There were, however, three female patients, aged 11 (Guthrie, 1945), 28 (Case 2), and 68 (Pitt, 1888).

Clinical Findings.-Little is known of the clinical aspects of this condition. Indeed, Case 5 of the present series is the first in which diffuse oesophageal hypertrophy has been recognized in life. In this case the relevant symptoms were dysphagia, regurgitation, and early morning or nocturnal mucus-vomits. Radioscopy (Professor Johnstone) four years after the onset of symptoms revealed diffuse lower oesophageal spasm with tertiary contractions. This spasm was also apparent during the passing of an oesophagoscope (Mr. Allison). At thoracotomy, three years later, the external appearance of the oesophagus was seen, and a biopsy established the presence of muscular hypertrophy. Symptoms persisted even after a high bilateral vagotomy. This had no apparent immediate effect, but 11 months after the operation the lower oesophagus was no longer spastic and seemed to behave like an " inert tube." Symptoms, however, still persisted, and the cachectic state of the patient and the fear of neoplasia led to the successful resection of the affected segment by Mr. Allison in 1951, nine years after the onset of dysphagia.

In only one other instance (Brücke, 1928) has dysphagia led to the radioscopic examination of the oesophagus. This was first performed in 1919, when no abnormality could be found, but nine years later a diffuse lower oesophageal spasm was demonstrated, accompanied by dilatation of the upper oesophagus and a filling defect at the junction of the two. The presence of the latter suggested carcinoma, and a " fistula " was made, after which death followed from bronchopneumonia. The cause of this filling defect proved to be an intramural myoma, a complication recognized in four other cases (Helmke, 1939).

In the remaining 30 cases the presence of an oesophageal lesion was unsuspected until revealed at necropsy. In several, there had been a terminal dysphagia (e.g., Case 2) overshadowed by other symptoms, while in one (Elliesen, 1903) it was found by questioning the patient's widow that there had been dysphagia for some 25 years. This observation emphasizes the variable and subjective nature of the appreciation of dysphagia, and probably explains the apparent absence of symptoms in so many cases. It is in accord with the findings of radiologists, for the radioscopic appearances of diffuse lower oesophageal spasm (Pickard, personal communication) and of cardiospasm or " achalasia" (Allison, 1953) have been encountered in the absence of any symptoms referable to the oesophagus.

Pathological Findings.-There is great and diffuse thickening of the lower oesophagus. Section of the wall reveals to the naked eye that this is due to a hypertrophy of the muscle coats and becomes obvious in the middle third, and in the lower third reaches as much as $1.5 \mathrm{~cm}$. in thickness. It commonly ends at the gastro-oesophageal mucosal junction, although in several instances (Rake, 1926; my Cases 4 and 5) it has ended several centimetres above this point. The lumen is of normal width or slightly narrowed, and there is no evidence of any obstructive lesion. There have been, however, two possible exceptions. Thus in Baillie's (1799) case there was a mucosal fold at the cardia, somewhat akin to the congenital mucosal folds occasionally seen at the pylorus, while in Case 5 in the present series there were two mucosal folds high in the resected segment of the oesophagus. Since there was never before 
vagotomy any radioscopic or endoscopic indication of these folds, it seems likely that they followed this operation and were due to relaxation of the wall of the oesophagus, and in particular of the muscularis mucosae, which was incorporated in the folds.

The essential histological change is simple hypertrophy of all muscular coats, and in particular of the inner muscular coat. In 12 out of the 25 cases examined microscopically, and in four of the five cases in this series, there was also a lymphocytic infiltration of the intermuscular septa in the region of Auerbach's plexus. In two instances this was slight (Brücke, 1928 (case 1); Helmke, 1939 (case 2)), but in 10 it was more severe (Rake, 1926 ; Helmke, 1939 (case 4) ; Bühler, 1943 (cases 1 and 3) ; Guthrie, 1945 ; Buccellato, 1948 ; and my cases 2, 3, 4, and 5). Eosinophil leucocytes were conspicuous in seven cases, and perhaps suggestive of an allergic aetiology. This infiltration, save in Rake's case, was focal and widespread and unassociated with fibrosis. In Rake's case, there was a chronic inflammatory fibrosis confined to the lowermost and unthickened portion of the oesophagus, and accompanied by local hypertrophy and deficiency of ganglia in Auerbach's plexus. This last change is of interest since it has been seen in cardiospasm (Lendrum, 1937) while an aganglionic segment in the large intestine has been held to be the essential abnormality in Hirschsprung's disease (e.g., by Bodian, Stephens, and Ward (1949). However, although myentericplexus lesions have repeatedly been sought in the cases of diffuse oesophageal hypertrophy under discussion, Rake's case is the only one in which such lesions have been found.

Pathogenesis.-This form of oesophageal hypertrophy is idiopathic in that there is no organic lesion at the cardia. It differs from cardiospasm (achalasia) in that the oesophagus is not dilated. Its pathogenesis is obscure and has given rise to a variety of speculations, some relating the hypertrophy to changes within the oesophagus, others to extra-oesophageal factors.

An inflammatory aetiology was first suggested in a brief reference to the condition made by Foerster (1863), but although a number of cases have shown cellular infiltration of the deep intermuscular septa, this finding has been inconstant, and there has never been evidence of peptic ulceration.

An alternative explanation for these cellular infiltrations is that they are a late and inconstant manifestation of an underlying muscular dysfunc- tion, and comparable to the lymphorrhages seen in skeletal muscle in myasthenia gravis. Dysphagia is, of course, a frequent symptom in $\frac{C}{0}$ myasthenia gravis, and has recently been shown $\overline{\bar{c}}$ to be associated with degenerative changes in the $\widetilde{\Phi}$ skeletal muscle of the upper oesophagus (Russell, 1953). Identical lesions were conspicuous in Case ${ }^{\text {s }}$ 3. Consequently, it seems reasonable to seek $\vec{\circ}$ evidence of myopathy in cases with diffuse oeso- $\overrightarrow{\vec{A}}$ phageal hypertrophy, and conversely, evidence of $\sigma_{\sigma}$ oesophageal hypertrophy in cases of myasthenia $\overrightarrow{\overrightarrow{2}}$ gravis. Although there is no certain evidence of ${ }_{0}^{x}$ either association, it is of interest that in Case $2 \dot{v}$ there was a thymoma, and in the abductor digiti $\vec{\omega}$ minimi muscle a lymphorrhage; for both theseo lesions are frequently encountered in myasthenia응 gravis. Further, in one of the necropsies performed on myasthenia gravis in this Institute the lowerc oesophagus was slightly thickened $(0.4 \mathrm{~cm}$.).

An alternative theory is that the condition is $\vec{G}$ neoplastic. A huge and distorted oesophagus: ${ }^{\perp}$ originally reported by Hall (1916) as a "diffuse oesophageal fibromyoma" conforms well with this theory, but it is difficult to regard the symmetrical and diffuse thickening of the muscular coats in the condition under discussion in a similar light. $\mathbb{\perp}$ Brücke (1928) did so, but neither Goedel (1929) nor Wood (1932) agreed with him. It is true that small myomata have been encountered in five $e_{\supset}$ instances (Brücke, loc. cit. ; Helmke, cases 1 to 4), but these could well be secondary to muscular hypertrophy. Their importance lies in the facto that they can cause radioscopic filling defects, and $\underset{x}{\tilde{D}}$ thus give rise to a mistaken diagnosis of carcinoma.

A congenital aetiology is a more plausible theory. It accounts well for the combination of jejunal, duodenal, pyloric, and oesophageal hypertrophy reported by Guthrie (1945) in a girl aged 11 years, $?$ and for the lone oesophageal hypertrophy recently? observed in an infant by Bodian (personal com munication). Curiously enough in six other cases o in addition to Guthrie's there was hypertrophy of the pylorus as well as of the oesophagus (Ehlers 1907 ; Helmke, 1939; Bühler, 1943 (cases 1, 2, and 3 ; my case 4 ). This combination is scarcely fortuitous, and indicates that the two lesions may have a common aetiology. They could be con- $\$$ genital, if it were accepted that infantile pyloric hypertrophy is a congenital malformation, capable of persisting into adult life. This hypothesis although speculative, merits investigation. It is? the more attractive because in affected infants i $\mathbb{B}$ is known that gastric dilatation may be followed by dilatation and hypertrophy of the oesophagus 
for example, a variable degree of oesophageal hypertrophy was noted in 26 of 57 necropsies performed on such infants in this department since 1909. Consequently, one could reasonably regard adults exhibiting oesophageal and pyloric hypertrophy as examples of the same sequence, the absence of dilatation being an expression of the more adequate musculature of the adult oesophagus.

It is difficult to reconcile this view with the frequent occurrence of idiopathic pyloric hypertrophy in adult life (Roessle, 1935). Such cases may be congenital, or they may, as Roessle suggested, be examples of vagal overaction. Neither hypothesis is supported by adequate factual evidence. Indeed, it is necessary to complicate the matter still further by noting that in Case 5 the pyloric hypertrophy was asymmetrical, and maximal on one aspect of the pylorus, thus approximating to the circumscribed form of pyloric hypertrophy which Bachmann (1952) has recently distinguished from the symmetrical variety described by Roessle.

Extra-oesophageal Factors.-Diffuse oesophageal hypertrophy has been a casual necropsy finding in a group consisting mainly of hospital patients in the later decades of life. There is a high incidence of concomitant cardiovascular hypertrophy, gastric or duodenal inflammation, and intestinal or pulmonary neoplasia. Intra-abdominal lesions included gastritis in three instances (Bühler, 1943, cases 1 and 2 ; Giampalmo, 1946), gastric or duodenal ulcers in three instances (Bühler, 1943, case 4 ; my cases 4 and 5), ulcerative colitis (Wood, 1932), and carcinoma of the large intestine in five instances (Reher, 1885; Bühler, 1943, cases 4 and 5 ; my cases 6 and 7). All these lesions could well have been coincidental.

The same is probably true of the occurrence of intrathoracic lesions, which included one bronchial carcinoma (case 1), one thymoma (case 2), sarcomatous metastases (case 3), and in 11 instances definite evidence of cardiovascular hypertrophy (Pitt, 1888 ; Rolleston, 1899 ; Ehlers, 1907 ; Brücke, 1928, case 2; Helmke, 1939, cases 1, 3, and 4; Bühler, 1943, case 1 ; Buccellato, 1948 ; my cases 3 and 4). Since in a further 10 instances there is equal evidence that the heart was not enlarged (Rake, 1926; Wood, 1932 ; Bühler, 1943, cases 4 and 5 ; Jemmi, 1947 ; my cases 1, 2, 5, 6, and 7), cardiac enlargement may surely be a fortuitous association. This, however, is not Helmke's view. He does not maintain that there is any mechanical pressure on the oesophagus, for this would not be likely to cause lower oesophageal hypertrophy, but rather postulates a reflex vagal overactivity, respon- sible alike for cardiac, oesophageal, and pyloric hypertrophy.

The frequent absence of cardiac hypertrophy is against, although it does not entirely exclude, this theory. Thus the definite, even if slow, loss of spasm in Case 5 following high bilateral vagotomy establishes for the first time in man the tonic effect of the vagi on the lower oesophagus. The evidence for this effect previously rested (Glas, 1929) on the results of vagal excitation and section in animals, and the association of cardiospasm with neoplastic involvement of the vagi in man. This latter association is, as Glas emphasized, of equivocal significance, since, without establishing destruction of both nerves it would be as reasonable to postulate vagal excitation as inhibition. Because of this difficulty little importance can be attached to the neuro-fibromatous involvement of the vagi in Scherrer's case of oesophageal hypertrophy (quoted by Bühler) or the envelopment of the vagi by thymoma in my second case.

Functional Nature of Diffuse Muscular HyPERTROPHY OF THE OESOPHAGUS.-The absence of any constant intrinsic or extrinsic lesion beyond simple muscular hypertrophy suggests that this condition is either a congenital abnormality, or that it is the result of a primary disorder of function. With regard to the latter, the simplest theory is that of Buccellato (1948), who, noting that his patient had been a voracious eater, attributed the muscular hypertrophy to overwork. There is no suggestion of such a history in any other case. On the other hand, the radiological evidence of spasm in my fifth case and in Brücke's first does support the conception of a physiological response to overwork, and thus indirectly Roessle's theory of vagal overactivity. Diffuse lower oesophageal spasm (Moersch and Camp, 1934) is not uncommon. It may cause dysphagia, but may also, as has been noted above, be asymptomatic. It seems probable that diffuse muscular hypertrophy, in view of its rarity, is a late complication of this spasm.

The question arises as to whether this spasm, whether accompanied by hypertrophy or not, is related to so-called "cardiospasm," a condition which in its fully developed stage is characterized by gross oesophageal dilatation. It has recently been shown in Leeds (Allison, 1953) that diffuse lower oesophageal spasm can give place to dilatation. It appears, therefore, that Rolleston (1899) was at least partly correct when he suggested that the variety of diffuse oesophageal hypertrophy under discussion is an early and still fully compensated stage of cardiospasm. 


\section{SUMMARY}

Seven examples of idiopathic diffuse muscular hypertrophy of the undilated oesophagus are added to the 25 previously recorded.

One of these was the first to be diagnosed in life. The presenting symptom was dysphagia. Radioscopy showed diffuse lower oesophageal spasm.

In one case there was also idiopathic pyloric hypertrophy, an association previously recorded in six other cases.

In four instances there was inflammation in the region of Auerbach's plexus throughout the oesophagus, and in one myonecroses in the skeletal muscle of the upper oesophagus.

The aetiology of this condition is obscure. Some cases are probably congenital, others idiopathic and acquired. The relationship of the latter to diffuse lower oesophageal spasm and "cardiospasm" is discussed.

It is a pleasure to acknowledge the help of Professor D. S. Russell in the preparation of this paper, and of Mr. A. Gallup for the photography. Grateful thanks are also due to Professor A. Lendrum for help with the manuscript; and to Mr. P. R. Allison,
Director of the Thoracic Unit, the General Infirmary at Leeds, and to Dr. J. S. Harris, Superintendent of Clabury Mental Hospital, for permission to publish their cases.

REFERENCES

Allison, P. R. (1953). In Medicine, ed. Garland, H. G., and Phillips, W., ist ed., p. 1118. Macmillan, London.

Bachmann, K. D. (1952). Beitr. path. Anat., 112, 97.

Baillie, M. (1799). A series of engravings, accompanied with. explanations, which are intended to illustrate the morbid anatomy of some of the most important parts of the human body. $1 \mathrm{st} \vec{\omega}$ of some of the most important parts
ed., p. 53. Bulmer and Co., London.

Bodian, M. Personal communication.

Stephens, F. D., and Ward, B. C. H. (1949). Lancet, 1, 6.

Brücke, H. von (1928). Virchow's Arch. path. Anat., 270, 880.

Buccellato, G. (1948). Pathologica, 40, 24.

Bühler, J. (1943). Schweiz. Z. Path. Bakt., 6, 193.

Ehlers, H. W. E. (1907). Virchows Arch. path. Anat., 189, 512.

Elliesen, (1903). Ibid., 172, 501.

Foerster, A. (1863). Handbuch der speciellen pathologischen Anatomie, 2nd ed., vol. 1, p. 65 . L. Voss, Leipzig.

Giampalmo, A. (1946). Inform. med., Genova, 1, 37.

Glas, E (1929). In Handbuch der Hals-, Nasen- Ohren-Heilkunde, ed Denker A and Kahler, O vol 9 p. 277. Springer, Berlin.

Goedel, A. (1929). Wien. med. Wschr., 79, 967.

Guthrie, K. J. (1945). Arch. Dis. Childh., 20, 176

Hall, A. J. (1916). Quart. J. Med., 9, 409.

Helmke, K. (1939). Virchows Arch. path. Anat., 304, 79

Jemmi, C. (1947). Oto-rino-laring, ital., 15, 348.

Lendrum, F. C. (1937). Arch. intern. Med., 59, 474. 43, 1165.

Pitt, G. N. (1888). Trans. path. Soc. Lond., 39, 107.

Pickard, C. Personal communication.

Rake, G. W. (1926). Guy's Hosp. Rep., 76, 145

Reher, H. (1885). Dtsch. Arch. klin. Med., 36, 455.

Roessle, R. (1935). Schweiz. med. W'schr., 16, 174.

Rolleston, H. D. (1899). Trans. path. Soc. Lond., 50, 69.

Russell, D. S. (1953). J. Path. Bact., 65, 279.

Scherrer. Quoted by Bühler, J. (See above.)

Wood, D. A. (1932). Arch. Path. Lab. Med., 14, 766. 